\title{
Phenotypic variability in a child with Felty's syndrome: a case report
}

\author{
Guo-min Li, Hai-mei Liu, Wan-zhen Guan, Yi-fan Li, Hong Xu and Li Sun ${ }^{*}$
}

\begin{abstract}
Background: Felty's syndrome (FS) is characterized by the triad of rheumatoid arthritis (RA), splenomegaly and neutropenia. The arthritis is typically severe and virtually always associated with high-titer rheumatoid factor. The presence of persistent neutropenia is generally required to make the diagnosis. Most patients diagnosed with FS are aged 50-70 years and have had RA for more than 10 years. It is rarely seen in patients with juvenile idiopathic arthritis (JIA), with only five cases having been reported throughout the world.

Case presentation: The present study describes the case of a 14-year-old female with a seven-year history of polyarticular JIA, presenting with splenomegaly, hepatomegaly, cholestasis and thrombocytopenia. However, she occasionally developed neutropenia. Titers of rheumatoid factor and anti-CCP were persistently high, and the antinuclear antibody titer was 1:320, while the antibody results for anti-dsDNA and anti-Sm were negative. Serum levels of IgA, IgG, IgM and IgE were all persistently elevated, and the ratio of CD19 $9^{+}$lymphocytes in the subgroups of lymphocytes was persistently high. The level of complements was normal. No STAT3 and STAT5B mutations were found by next-generation sequencing. The patient did not respond to methotrexate, prednisolone, hydroxychloroquine (HCQ), sulfasalazine and etanercept but was responsive to rituximab.

Conclusions: JIA, thrombocytopenia and splenomegaly are the most common and important features in six children with FS, while persistent neutropenia is not seen in all these patients. No complement deficiency has been found in children with FS so far. Manifestations of FS without neutropenia may be extremely rare. There are differences between adults and children in the clinical and laboratory features of FS.
\end{abstract}

Keywords: Children, Felty's syndrome, Juvenile idiopathic arthritis, Thrombocytopenia

\section{Background}

Felty's syndrome (FS) was first described in 1924 at Johns Hopkins hospital by the American physician, Augustus Roi Felty [1]. The term was first used by Hanrahan and Miller in 1932 when they described the beneficial effect of splenectomy in a patient with features similar to the five cases reported by Felty. It is a specific subcategory of rheumatoid arthritis (RA) characterized by the triad of seropositive RA with severe joint involvement, splenomegaly and neutropenia. Typically, FS tends to affect patients with long-

\footnotetext{
* Correspondence: lillysun@263.net

Department of Rheumatology, Children's Hospital of Fudan University, 399 Wan-yuan Road, Shanghai 201102, China
}

standing erosive RA. It usually develops after a $>10$ year course of RA [2], with increased risk in patients with a positive family history of RA. The complete triad is not an absolute requirement, but persistent neutropenia with an absolute neutrophil count (ANC) less than $1500-2000 / \mathrm{mm}^{3}$ is generally regarded as necessary for establishing the diagnosis in adult [3]. FS affects $1-3 \%$ of patients with RA, but it is rarely seen in patients with juvenile idiopathic arthritis (JIA), with only a few cases having been reported throughout the world [4-8]. The active extra-joint clinical features can be misleading in FS, and certain pediatrician focus on severe extra-articular disease and neutropenia, which suggests infectious diseases. Thus, the

(c) The Author(s). 2020 Open Access This article is licensed under a Creative Commons Attribution 4.0 International License, which permits use, sharing, adaptation, distribution and reproduction in any medium or format, as long as you give appropriate credit to the original author(s) and the source, provide a link to the Creative Commons licence, and indicate if changes were made. The images or other third party material in this article are included in the article's Creative Commons licence, unless indicated otherwise in a credit line to the material. If material is not included in the article's Creative Commons licence and your intended use is not permitted by statutory regulation or exceeds the permitted use, you will need to obtain permission directly from the copyright holder. To view a copy of this licence, visit http://creativecommons.org/licenses/by/4.0/. The Creative Commons Public Domain Dedication waiver (http://creativecommons.org/publicdomain/zero/1.0/) applies to the data made available in this article, unless otherwise stated in a credit line to the data. 
correct diagnosis is occasionally challenging for children rheumatologist. We describe an additional case of a child with FS, compare it to the previous reports, and discuss differences between adults and children in clinical and laboratory features of FS through a literature review, in order to better understand the disease.

\section{Case presentation}

The patient, an 8-year-old Chinese girl, presented with pain of the left hip in Jan 2011, which resolved spontaneously over several weeks. Seven months later, she presented with pain of the left hip again. She was diagnosed with JIA because of the chronic synovitis of the left hip joint at the local hospital in Jan 2012. She had high titers of RF and anti-CCP, while her complete blood count was normal at that time. Clinical examination revealed splenomegaly. Treatment was initiated with diclofenac sodium $(2-3 \mathrm{mg} / \mathrm{kg} /$ day $)$, methotrexate $\left(10-15 \mathrm{mg} / \mathrm{m}^{2} /\right.$ week) and hydroxychloroquine $(5 \mathrm{mg} / \mathrm{kg} /$ day $)$. Her symptoms improved within 3 months, and treatment was stopped by her parents in Oct 2012. However, she presented with pain and swelling in the hips, knees, ankles and wrists in Jan 2013. In addition, she gradually developed morning stiffness and synovitis of proximal interphalangeal joints and metacarpophalangeal joints. An abdominal ultrasound revealed hepatomegaly and splenomegaly. She was given oral prednisolone $(1 \mathrm{mg} /$ $\mathrm{kg} /$ day) combined with diclofenac sodium, methotrexate and hydroxychloroquine. Within several months, the patient had almost no pain or stiffness and minimal joint swelling on examination. However, the proximal interphalangeal and metacarpophalangeal joints gradually developed deformities. Complete blood counts were obtained every 4 to 6 weeks over the next year and showed persistent thrombocytopenia (range from 48 to $\left.94 \times 10^{9} / \mathrm{L}\right)$ but no neutropenia. She received etanercept $(0.8 \mathrm{mg} / \mathrm{kg} /$ week) treatment in Jan 2014 due to progressive aggravation of joint deformity. She was admitted to our hospital for further assessment due to the chronic synovitis of her joints, hepatosplenomegaly and thrombocytopenia in Jul 2015. On admission, blood tests revealed a white blood cell count of $6.2 \times 10^{9} / \mathrm{L}$ with an absolute neutrophil count of $3.92 \times 10^{9} / \mathrm{L}$, hemoglobin levels of $118 \mathrm{~g} / \mathrm{L}$ and a platelet count of $95 \times 10^{9} / \mathrm{L}$. The peripheral blood smear was normal. A bone marrow aspirate showed normal trilineage hematopoiesis with no infiltration malignant cells or large granular lymphocytes. Levels of glutamic oxaloacetic transaminase and glutamate pyruvate transaminase were normal, while total bilirubin levels were $43.1 \mu \mathrm{mol} / \mathrm{L}$ (normal range 3.4-17.1), direct bilirubin levels were $18.7 \mu \mathrm{mol} / \mathrm{L}$ (normal range 0-6) and total bile acid levels were $203.0 \mu \mathrm{mol} / \mathrm{L}$ (normal range0-10). A rapid erythrocyte sedimentation rate $(E S R, 35 \mathrm{~mm} / \mathrm{h}$ ) and high C-reactive protein levels (CRP, $60.2 \mathrm{mg} / \mathrm{l}$ ) were revealed. Tests for human immunodeficiency virus, syphilis, hepatitis B, hepatitis $\mathrm{C}$ and autoimmune hepatitis-associated antibodies and a purified protein derivative skin test produced negative findings. The antinuclear antibody titer was 1:100, while the results for anti-dsDNA, anti-Sm and anti-Rnp antibodies were negative. Levels of complement C3 and C4 were normal. Serum levels of IgA were $2.97 \mathrm{~g} / \mathrm{L}, \operatorname{IgG} 15.49 \mathrm{~g} / \mathrm{L}$, IgM $2.39 \mathrm{~g} / \mathrm{L}$ and IgE 319.1 $\mathrm{g} / \mathrm{L}$ and were all elevated. Levels of rheumatoid factor and antibodies to cyclic citrullinated peptides were 10 , $200.0 \mathrm{U} / \mathrm{L}$ and $384.0 \mathrm{U} / \mathrm{L}$, respectively. X-rays of the hand joints showed soft tissue swelling, bone erosion and narrowing of the joint cavity. A physical examination revealed splenomegaly, hepatomegaly and deformities in the proximal interphalangeal joints, metacarpophalangeal joints, wrists and ankles (Fig. 1a

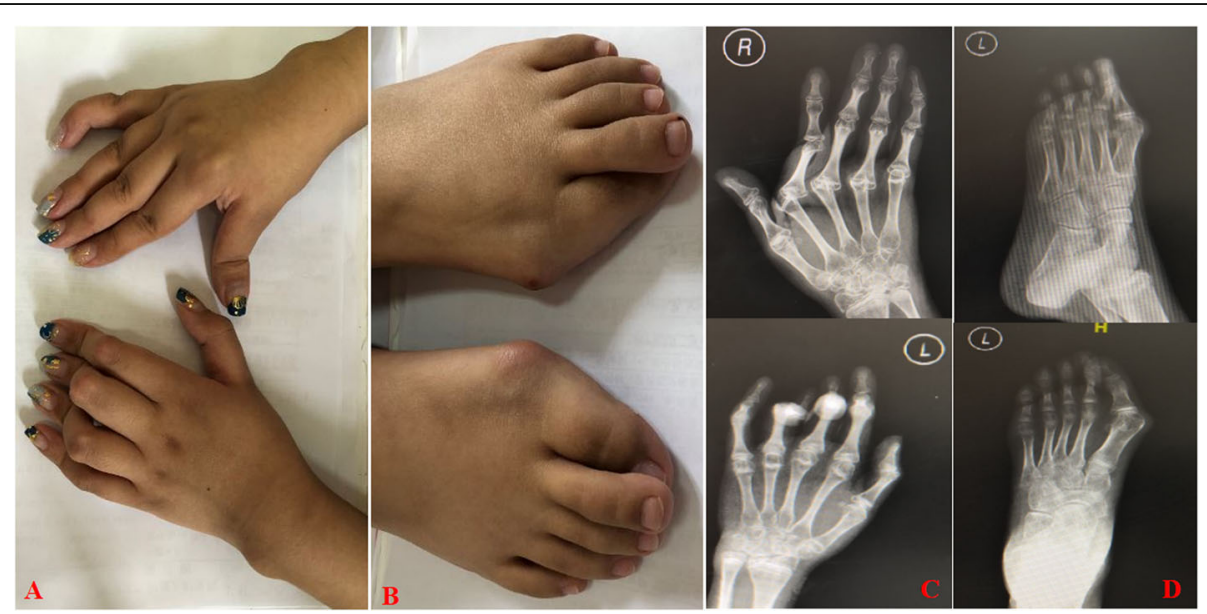

Fig. 1 a shows deformities in the proximal interphalangeal joints and wrists, and $\mathbf{b}$ shows deformities in the metacarpophalangeal joints and ankles; $\mathbf{c}$ reveals deformities of left and right hands, and $\mathbf{d}$ reveals deformities of left foot form positive and lateral position by $\mathbf{X}$-rays 
and $\mathrm{b}$ ), which were confirmed by X-rays and computed tomography (Fig. $1 \mathrm{c}, \mathrm{d}$ and Fig. 2), respectively. Examination of the other systems was unremarkable, such as no peripheral and central lymph nodes of enlargement. Hydroxychloroquine and etanercept were stopped, prednisolone and methotrexate were maintained at $15 \mathrm{mg}$ daily and $15 \mathrm{mg}$ weekly, respectively, and sulfasalazine was added at $20 \mathrm{mg} / \mathrm{kg}$ daily. Treatment with rituximab was started twice at $375 \mathrm{mg} / \mathrm{m}^{2}$ over 2 weeks in July 2015 and then once at $375 \mathrm{mg} / \mathrm{m}^{2}$ every 6 months. One month after the start of treatment, CRP decreased from $60.2 \mathrm{mg} / \mathrm{L}$ to $6 \mathrm{mg} / \mathrm{L}$, and the ESR decreased from 35 $\mathrm{mm} / \mathrm{h}$ to $8 \mathrm{~mm} / \mathrm{h}$. Over 6 months, the prednisone was tapered to her current dose of $7.5 \mathrm{mg} /$ day.

The results of previous clinical and laboratory evaluations were obtained from earlier outpatient records. Pertinent results from the last three consecutive years are shown in Fig. 3. Since the onset of her arthritis, the total white blood cell (WBC) count was normal and occasionally below $4.0 \times 10^{9} / \mathrm{L}$. Regular follow-up visits were scheduled for her after Jan 2016. Although her ESR, $\mathrm{CRP}$ and count of $\mathrm{CD} 19^{+}$lymphocytes fell transiently to the normal range after treatment with rituximab, they rose before the next treatment (see Fig. 3). Titers of RF (see Fig. 3) and levels of all immunoglobulins (see Table 1) were persistently high. The ratio of CD19+ lymphocytes in subgroups of lymphocytes were persistently high, while the count of $\mathrm{CD} 16^{+} \mathrm{CD} 56^{+}$lymphocytes was persistently below the normal range. She experienced a fever, rising ESR and CRP, increasing RF $(68,000 \mathrm{U} / \mathrm{L})$ and anti-CCP $(320 \mathrm{U} / \mathrm{L})$ titers, and falling $\mathrm{WBC}$ and platelet count in July 2018. However, she had no hyperferritinemia, hypertriglyceridemia, hypofibrinogenemia. Rituximab $375 \mathrm{mg} / \mathrm{m}^{2}$ every 6 months was adjusted to the same dosage every 4 months. Since then, her neutrophil count, platelet count, ESR and CRP have been in a persistently normal range. Next-generation sequencing was performed in July 2018 because she presented with refractory FS. No STAT3 or STAT5B mutations were found.

\section{Discussion and conclusion}

The PubMed database was searched for all publications with the keywords or MeSH terms "Felty's syndrome" AND "pediatric" or "child". Only English language articles were included. We also searched the Chinese Journal Full-text Database (CNKI) using the same keywords in Chinese. A few case studies for children with FS have been published in English, but no Chinese studies were found. We performed a literature review and identified 5 children with FS [4-8]. Table 2 shows the major features of these cases. Six children with FS have been identified, and all of these cases are female. The average age at onset of JIA is only 9.2 years (range from 4.0-15.0), and the duration of JIA until FS is 6.2 years (range from 4.0-15.0).

FS is an uncommon but severe extra-articular manifestation of rheumatoid arthritis, including hepatopathy, lymphadenopathy, vasculitis, leg ulcers, abnormal skin pigmentation and a high frequency of rheumatoid nodules $[2,9]$. There is no specific diagnostic criterion for FS. FS is a clinical diagnosis in patients with RA or JIA with unexplained neutropenia and splenomegaly $[2,10]$.

Although the patient in our study presented with hip arthritis, she gradually developed morning stiffness and synovitis of proximal interphalangeal joints and metacarpophalangeal joints. Not only that, she had high RF and

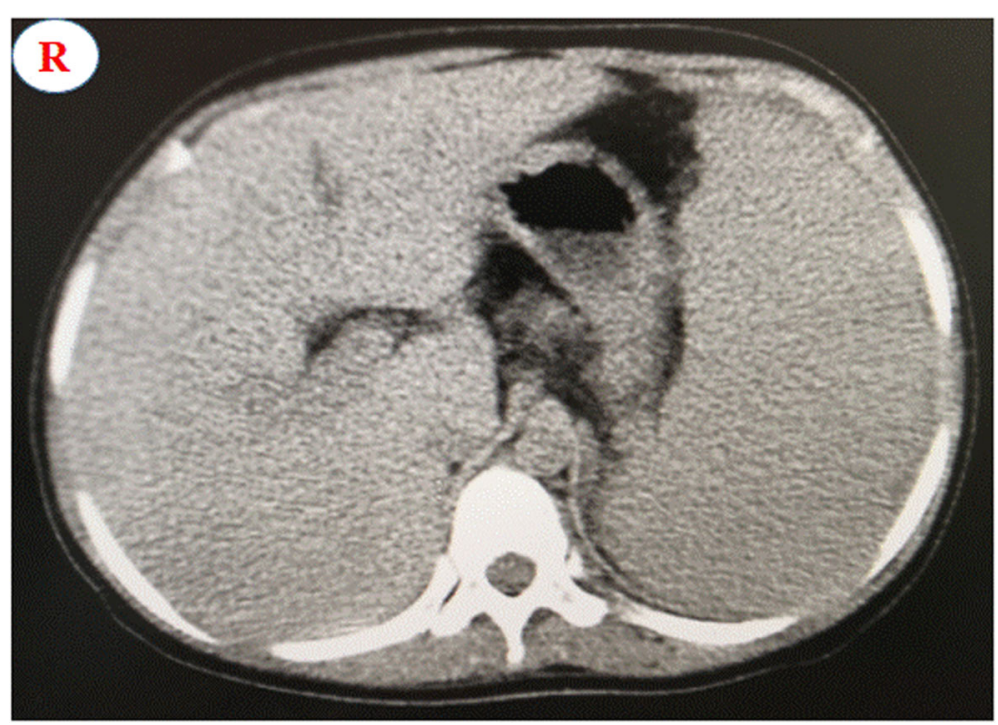

Fig. 2 Abdominal contrast-enhanced CT revealed splenomegaly 


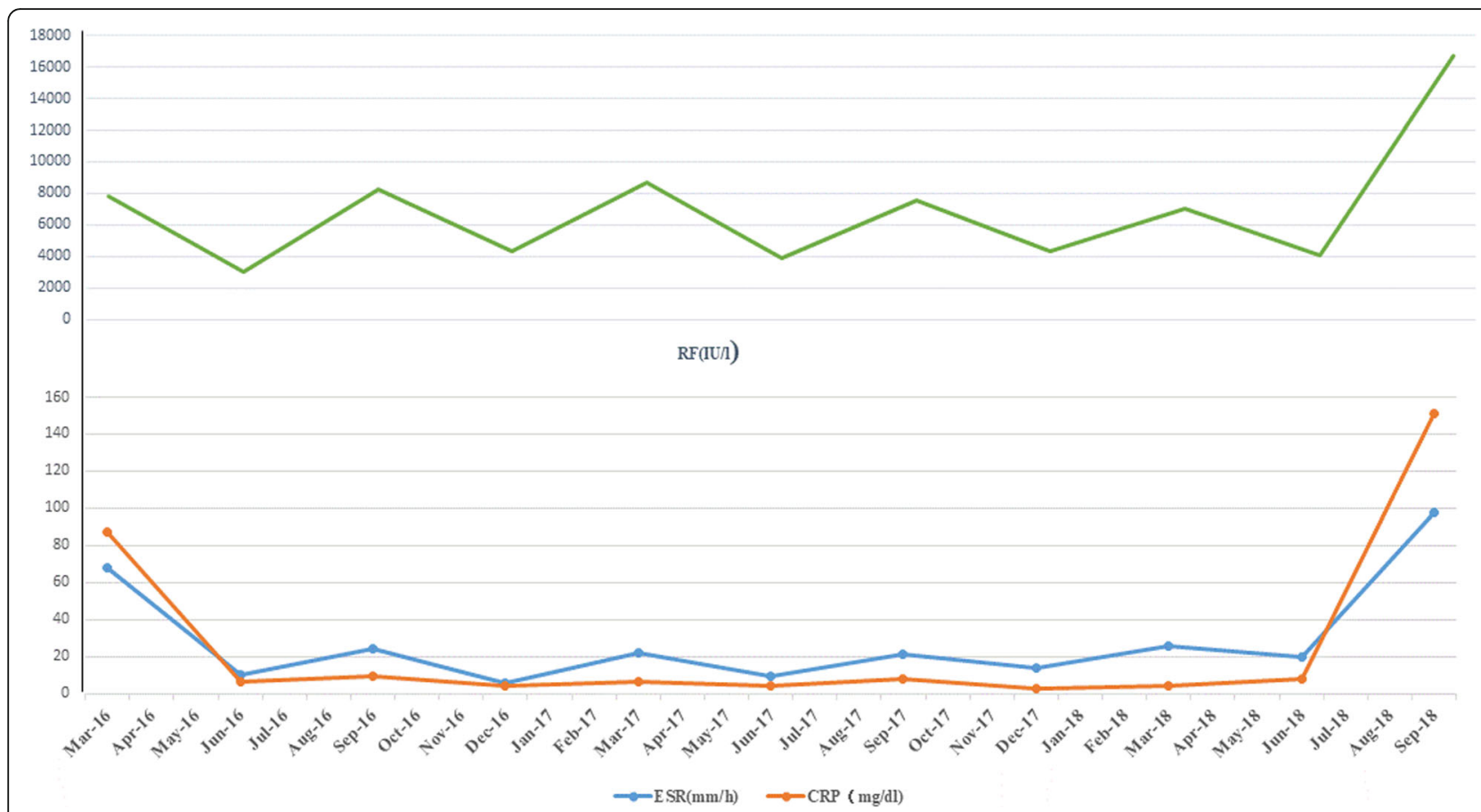

Fig. 3 Following-up of ESR, CRP and RF after treatment with rituximab. They fell transiently to a normal range after treatment and rose before the next treatment

anti-CCP titers. Thus, she fulfills polyarthritis (rheumatoid factor positive) of 2001 ILAR juvenile idiopathic arthritis classification [11]. In addition, she had splenomegaly, neutropenia and thrombocytopenia. Bone marrow aspirate and peripheral blood smear ruled out large granular lymphocyte syndrome, hematological neoplasm, and suppression of hematopoiesis by medications (such as methotrexate). Therefore, she met the diagnosis criteria of FS. However, our patient presented with occasional neutropenia rather than persistent neutropenia. Recurrent thrombocytopenia was more common than occasional neutropenia in the patient. Some laboratory features of our patient overlap with systemic lupus erythematosus (SLE), such as neutropenia, thrombocytopenia and positive ANA. However, the ANA titer was low (1:320), and the results of antidsDNA and anti-Sm antibodies were negative, which did not support the diagnosis of SLE. Although she experienced a fever, falling WBC and platelet count, and splenomegaly, she had no hyperferritinemia, hypertriglyceridemia, hypofibrinogenemia. In addition, no hemophagocytic cells were found by bone marrow aspiration. Therefore, she was not diagnosed with macrophage activation syndrome (MAS).

Current data show that $1-3 \%$ of RA patients are complicated with FS, with an estimated prevalence of 10 per 100,000 populations [12]. FS is rarely seen in patients with JIA, with only five cases having been reported throughout the world [4-8]. Table 2 provides a comparison of these five patients with our patient (patient 6). The six patients were all female. Although patient 4 had arthritis in the adolescent period, she developed FS in the adult period. Patient 6 and patient 1 developed seropositive $(\mathrm{RF}+)$ JIA, and the other four patients developed seronegative (RF-) JIA. Except for patient 4 with systemic JIA, patient 6 and the other four patients had polyarticular JIA. All six patients had splenomegaly, while patient 6 , patient 1 and patient 2 had hepatomegaly. Patient 6 developed occasional neutropenia, which differed from other five patients, of which four had

Table 1 Immunoglobulin subgroups

\begin{tabular}{|c|c|c|c|c|c|c|c|c|c|c|c|}
\hline \multirow[t]{2}{*}{ Immunoglobulin } & \multicolumn{3}{|c|}{$2016(y)$} & \multicolumn{4}{|l|}{$2017(y)$} & \multicolumn{3}{|c|}{$2018(y)$} & \multirow{2}{*}{$\begin{array}{l}\text { Normal } \\
\text { range }\end{array}$} \\
\hline & $04 / 08$ & $23 / 09$ & $01 / 12$ & $13 / 07$ & $28 / 08$ & $09 / 10$ & $16 / 11$ & $01 / 03$ & $10 / 09$ & $27 / 09$ & \\
\hline $\lg A(g / L)$ & 2.86 & 2.97 & 1.76 & 3.38 & 4.18 & 3.55 & 2.88 & 5.01 & 6.34 & 5.45 & $0.52-2.16$ \\
\hline $\lg G(g / L)$ & 14.41 & 15.49 & 11.62 & 14.60 & 16.0 & 16.1 & 14.4 & 15.4 & 20.8 & 17.0 & $6.09-12.85$ \\
\hline $\lg M(g / L)$ & 2.21 & 2.39 & 1.09 & 4.39 & 5.89 & 3.81 & 3.19 & 7.39 & 9.45 & 7.25 & $0.67-2.01$ \\
\hline $\lg E(K U / L)$ & 112.6 & 319.1 & 71.7 & 141.36 & 346.7 & 147.2 & 314.48 & 269 & 4280.14 & 1949.12 & $<100$ \\
\hline
\end{tabular}


Table 2 clinical features of six children with FS

\begin{tabular}{|c|c|c|c|c|c|c|}
\hline Clinical features & Case 1 & Case 2 & Case 3 & Case 4 & Case 5 & Case 6 \\
\hline Age at onset of JIA(Y) & 10.0 & 4.0 & 4.0 & 14.0 & 15.0 & 8.0 \\
\hline Gender & $\mathrm{F}$ & $\mathrm{F}$ & $\mathrm{F}$ & $\mathrm{F}$ & $\mathrm{F}$ & $\mathrm{F}$ \\
\hline JIA subtype & Polyarticular & Polyarticular & Polyarticular & Systemic & Polyarticular & Polyarticular \\
\hline Duration of JIA until FS(Y) & 5.8 & 11.0 & 4.5 & 10.0 & 2.0 & 4.0 \\
\hline Splenomegaly & Yes & Yes & Yes & Yes & Yes & Yes \\
\hline Hepatomegaly & No & No & No & Yes & Yes & Yes \\
\hline Hemoglobin(g/l) & Normal & 135.0 & 122.0 & 128.0 & 80.0 & 118.0 \\
\hline Platelet count $\left(\times 10^{9} / \mathrm{l}\right)$ & Not reported & 313.0 & 72.0 & 105.0 & 159.0 & 95.0 \\
\hline Leucocyte count $\left(\times 10^{9} / \mathrm{l}\right)$ & 1.8 & 4.1 & 2.8 & 2.7 & 4.1 & 6.2 \\
\hline Granulocyte count $\left(\times 10^{9} / l\right)$ & 0.5 & 1.7 & 1.3 & 1.5 & 3.1 & 3.92 \\
\hline RF (IU/I) & 1:480 Positive & Negative & Negative & Negative & Negative & 10,200.0 Positive \\
\hline Anti-CCP(U/l) & Not reported & Not reported & Not reported & Not reported & Negative & 384.0 \\
\hline Levels of complement & Normal & NA & Normal & NA & Normal & Normal \\
\hline ANA & 1:120 Positive & 1:320 Positive & Negative & Negative & Negative & 1:320 Positive \\
\hline Bone marrow findings & Normal & Normal & Normal & Normal & Normal & Normal \\
\hline Medications & MTX, Ibuprofen & Gold, HCQ, ASA & Tolmetin, ASA & $\begin{array}{l}\text { Prednisolone, HCQ, } \\
\text { Ibuprofen, MTX }\end{array}$ & MTX, HCQ, MP & $\begin{array}{l}\text { Prednisolone, Diclofenac, } \\
\text { HCQ, Sulfasalazine, MTX, } \\
\text { Etanercept, Rituximab }\end{array}$ \\
\hline Reference & [4] & {$[5]$} & [6] & [7] & [8] & * \\
\hline
\end{tabular}

MTX Methotrexate, HCQ Hydroxychloroquine, ASA Acetylsalicylic acid, MP Methylprednisolone; *, our patient

persistent neutropenia and one had no neutropenia. Patient 6, patient 3 , and patient 4 all had thrombocytopenia. The level of hemoglobin was below the normal range only in patient 5 .

Adult FS is three times more common in females [2], but most children with FS have been females so far. Adults diagnosed with FS are usually $50-70$ years of age and have had RA for more than 10 years $[9,13]$, while the average age at onset of JIA is only 9.2 years (range from 4.0-15.0), and the duration of JIA until FS is 6.2 years (range from 4.0-15.0). Therefore, FS usually develops late in RA and JIA. Although FS is a severe form of RA, it can be asymptomatic. In very rare and adult cases, manifestations of FS had no clinical but only laboratory features of RA [13-16]. Therefore, joint involvement is not necessary for diagnosis and is absent in $15-40 \%$ of FS patients [2]. To date, FS without arthritis has not been reported in children. Splenomegaly is not always present in adult FS [8], but it occurs in all children with FS. Neutropenia is the most common and important feature of FS. Some authors consider all RAassociated neutropenia to be laboratory manifestations of FS $[2,9,15,17]$. The complete triad is not an absolute requirement, but persistent neutropenia is necessary for establishing the diagnosis [3]. Of the six children with FS, one had no neutropenia, one had transient neutropenia, and the others had persistent neutropenia; thus, persistent neutropenia is not necessary for diagnosis in children. Thrombocytopenia is a common manifestation in children with FS, yet it seldom occurs in adults [2] (see Table 3). High titers of rheumatoid factor are present in most adult patients. Of the 72 patients with FS reviewed by Spivak, 94\% had positive test results for rheumatoid factor and $63 \%$ had antinuclear antibodies [18], while 2 out of 6 children with FS had positive test results for rheumatoid factor and 3 out of 6 children had antinuclear antibodies. Complement components are usually depressed in adults with FS [2], but they are normal in children. Therefore, there are differences between adults and children in clinical and laboratory features of FS, and they are summarized in Table 3 .

Although the precise pathophysiology of FS remains unknown, an autoimmune mechanism seems likely. The syndrome occurs almost exclusively in patients who have abnormal circulating autoantibodies, either rheumatoid factor, antinuclear antibodies, or both [19]. Our study showed that the levels of all immunoglobulin subgroups (see Table 1) and the ratio of $\mathrm{CD} 19^{+}$lymphocytes in subgroups of lymphocytes were persistently high in the patient, which supported that the autoimmune mechanism plays an important role in FS. Interestingly, all subgroups of immunoglobulin are elevated in patients, even immunoglobulin E (IgE). Raised levels of serum IgE and eosinophils are known as hallmarks in atopic patients. Anti-IgG antibodies (anti-IgG) of the IgE class, studied in sera from patients with JIA, in patients with RA and FS using an indirect immunofluorescence technique, 
Table 3 Difference between adults and children in clinical and laboratory features of FS

\begin{tabular}{|c|c|c|c|c|c|c|c|c|}
\hline Patient & F/M ratio & Arthritis & Splenomegaly & Leukopenia & Thrombocytopenia & Anemia & Hypocomplementemia & Autoantibody \\
\hline Adults & $2-3 / 1$ & common & common & Neutropenia (Always) & Rare & Present & Frequent & common \\
\hline Children & All F & in all six & in all six & Neutropenia (Often) & Often & Present & None & three out of six \\
\hline
\end{tabular}

showed IgE anti-IgG in $63 \%$ of patients with RA and in $80 \%$ of patients with FS [20]. The titers of IgE anti-IgG were significantly higher in the FS patients. Therefore, IgE anti-IgG may be regarded as part of a broad polyclonal antibody response to IgG molecules in FS patients [21].

There is no standard therapy for this disease, and several disease-modifying antirheumatic drugs have been used with varying success. MTX has been considered a first-line therapy for FS since Wassenberg et al. [22] reported the efficiency of a low dose in five of seven RA patients with FS. However, the MTX response was inconsistent, as it is in this case. Several alternative drugs - prednisolone, HCQ and etanercept - have been proposed [23, 24]. Unfortunately, our patient showed no response to prednisolone, HCQ and etanercept, as was previously observed $[25,26]$. Rituximab, a chimeric antiCD20 monoclonal antibody, is used in combination with methotrexate to treat active RA after failure or intolerance of at least one anti-TNF- $\alpha$ [27]. Therefore, HCQ and etanercept were switched to rituximab. Treatment with rituximab was started twice at $375 \mathrm{mg} / \mathrm{m}^{2}$ over 2 weeks and then once at $375 \mathrm{mg} / \mathrm{m}^{2}$ every 6 months. Although ESR and CRP rapidly decreased to the normal range after initial treatment with rituximab, they were elevated before the next treatment in the patient (see Fig. 3). Treatment with rituximab was adjusted to 375 $\mathrm{mg} / \mathrm{m}^{2}$ every 4 months. The patient is being followed up closely. Until August 2019, her neutrophil count, platelet count, ESR and CRP have been in a persistently normal range, and joints had no swelling and pain.

Recently, somatic STAT3 and STAT5B mutations were discovered in $30-40 \%$ of patients with large granular lymphocyte leukemia [28, 29], and somatic STAT3 mutations were detected in $43 \%$ of FS patients with deep amplicon sequencing targeting all STAT3 exons [30]. Mutations were located in the SH2 domain of STAT3, which is a known mutational hotspot. We performed next-generation sequencing in the patient because she presented with refractory FS. However, no STAT3 mutations were found. This is concurrent with a study showing that in a cohort of 82 newly diagnosed RA patients, no STAT3 mutations were detected [31].

Here, we descripted FS girl without persistent neutropenia and low levels of complement. Manifestations of FS without neutropenia may be extremely rare. We only found six children with FS reported through literature review (including our patient), hence FS is rarely seen in children with JIA. JIA, thrombocytopenia and splenomegaly are the most common and important features in six children with FS, while persistent neutropenia is not seen in these patients. Low levels of complement are not found in any children with FS so far. There are differences between adults and children in the clinical and laboratory features of FS.

\section{Abbreviations \\ ANC: Absolute neutrophil count; CRP: C-reactive protein levels; ESR: Erythrocyte sedimentation rate; FS: Felty's syndrome; \\ HCQ: Hydroxychloroquine; JIA: Juvenile idiopathic arthritis; RF: Rheumatoid factor; RA: Rheumatoid arthritis; WBC: White blood cell}

Acknowledgements

Many thanks to the patient and her parents.

Availability of data and materials.

The datasets are not publicly available but are available from the first author on reasonable request.

\section{Authors' contributions}

LS, G-m L participated in research design. Y-f L, G-w Z, G-mL, LS and H-mL participated in the writing of the paper. $\mathrm{HX}, \mathrm{G}-\mathrm{mL}$, and $\mathrm{LS}$ participated in data analysis. All authors read and approved the final manuscript.

\section{Funding}

This work was not supported by any project.

\section{Ethics approval and consent to participate}

The patients' parents provided written informed consent. Ethics board approval and consent was obtained for this work from the Ethics Committee at the Children's Hospital of Fudan University, Shanghai, China (ekyy-201169).

\section{Consent for publication}

Written informed consent was obtained from the patient's parent for publication of this case report and any accompanying images.

\section{Competing interests}

The authors declare that they have no competing interests.

Received: 19 December 2019 Accepted: 26 March 2020

Published online: 07 April 2020

\section{References}

1. Maccormac H. Chauffard-still-Felty syndrome. Proc R Soc Med. 1938;31:4734.

2. Owlia MB, Newman K, Akhtari M. Felty's syndrome, insights and updates. Open Rheumatol J. 2014:8:129-36.

3. Campion G, Maddison PJ, Goulding N, James I, Ahern MJ, Watt I, et al. The Felty syndrome: a case-matched study of clinical manifestations and outcome, serologic features, and immunogenetic associations. Medicine. 1990;69:69-80.

4. Rosenberg AM, Mitchell DM, Card RT. Felty's syndrome in a child. J Rheumatol. 1984;11:835-7.

5. Toomey K, Hepburn B. Felty syndrome in juvenile arthritis. J Pediatr. 1985; 106:254-5.

6. Bloom BJ, Smith P, Alario AJ. Felty syndrome complicating juvenile rheumatoid arthritis. J Pediatr Hematol Oncol. 1998;20:511-3. 
7. Lee $\mathrm{CH}$, Han $\mathrm{SH}$, Yoon BY, Lee YW. A case of adult-onset Felty syndrome in juvenile rheumatoid arthritis. Pediatr Int. 2005;47:463-5.

8. Xiao RZ, Xiong MJ, Long ZJ, Fan RF, Lin DJ. Diagnosis of Felty's syndrome, distinguished from hematological neoplasm: a case report. Oncol Lett. 2014; 7:713-6.

9. Woolston W, Connelly LM. Felty's syndrome: a qualitative case study. Medsurg Nurs. 2017;26(105-109):118.

10. Balint GP, Balint PV. Felty's syndrome. Best Pract Res Clin Rheumatol. 2004; 18:631-45.

11. Berntson L, Fasth A, Andersson-Gäre B, Kristinsson J, Lahdenne P, et al. Construct validity of ILAR and EULAR criteria in juvenile idiopathic arthritis: a population based incidence study from the Nordic countries. International League of Associations for Rheumatology European League Against Rheumatism. J Rheumatol. 2001;28:2737-43.

12. Calguneri M, Ureten K, Ozturk MA, Onat AM, Ertenli I, Kiraz S, et al. Extraarticular manifestations of rheumatoid arthritis: results of a university hospital of 526 patients in Turkey. Clin Exp Rheumatol. 2006;24:305-8.

13. Rozin A, Hoffman R, Hayek T, Balbir-Gurman A. Felty's syndrome without rheumatoid arthritis? Clin Rheumatol. 2013;32:701-4.

14. Chavalitdhamrong D, Molovic-Kokovic A, lliev A. Felty's syndrome as an initial presentation of rheumatoid arthritis: a case report. Cases J. 2009;2:206.

15. Jain T, Mittal C, Sengupta R, Rubin B. Non-articular Felty's syndrome: an uncommon diagnosis. Neth J Med. 2015;73:435-6.

16. Bradley JD, Pinals RS. Felty's syndrome presenting without arthritis. Clin Exp Rheumatol. 1983;1:257-9.

17. Aslam F, Cheema RS, Feinstein M, Chang-Miller A. Neutropaenia and splenomegaly without arthritis: think rheumatoid arthritis. BMJ Case Rep. 2018. bcr-2018-225359.

18. Spivak JL. Felty's syndrome: an analytical review. Johns Hopkins Med J. 1977; 141:156-62.

19. Dwivedi N, Radic M. Citrullination of autoantigens implicates NETosis in the induction of autoimmunity. Ann Rheum Dis. 2014;73:483-91.

20. Egeskjold EM, Permin H, Nielsen I, Sørensen HJ, Osterballe O, Kallerup HE. Anti-lgG antibodies and antinuclear antibodies in allergic patients. Allergy. 1981:36:573-81.

21. Permin H, Egeskjold EM. IgE anti-lgG antibodies in patients with juvenile and adult rheumatoid arthritis including Felty's syndrome. Allergy. 1982;37: 421-7.

22. Wassenberg S, Herborn G, Rau R. Methotrexate treatment in Felty's syndrome. Br J Rheumatol. 1998;37:908-11.

23. Mahévas M, Audia S, De Lastours V, Michel M, Bonotte B, Godeau B. Neutropenia in Felty's syndrome successfully treated with hydroxychloroquine. Haematologica. 2007;92:e78-9.

24. Ghavami A, Genevay S, Fulpius T, Gabay C. Etanercept in treatment of Felty's syndrome. Ann Rheum Dis. 2005;64:1090-1.

25. Heylen L, Dierickx D, Vandenberghe P, Westhovens R. Targeted therapy with rituximab in Felty's syndrome: a case report. Open Rheumatol J. 2012;6:312-

26. Shipley E, Héraud A, Hennette A, Vernhes JP. Efficacy of rituximab in Felty's syndrome. Joint Bone Spine. 2008:75:621-2.

27. Edwards JC, Szczepanski L, Szechinski J, Filipowicz-Sosnowska A, Emery P, Close DR, et al. Efficacy of B-cell-targeted therapy with rituximab in patients with rheumatoid arthritis. N Engl J Med. 2004;350:2572-81.

28. Rajala HL, Olson T, Clemente MJ, Lagström S, Ellonen P, Lundan T, et al. The analysis of clonal diversity and therapy responses using STAT3 mutations as a molecular marker in large granular lymphocytic leukemia. Haematologica. 2015;100:91-9

29. Rajala HL, Eldfors $\mathrm{S}$, Kuusanmaki $\mathrm{H}$, van Adrichem AJ, Olson T, Lagström $\mathrm{S}$, et al. Discovery of somatic STAT5b mutations in large granular lymphocytic leukemia. Blood. 2013;121:4541-50.

30. Savola P, Brück O, Olson T, Kelkka T, Kauppi MJ, Kovanen PE, et al. Somatic STAT3 mutations in Felty syndrome: an implication for a common pathogenesis with large granular lymphocyte leukemia. Haematologica. 2018;103:304-12

31. Savola P, Kelkka T, Rajala HL, Kuuliala A, Kuuliala K, Eldfors S, et al. Somatic mutations in clonally expanded cytotoxic T lymphocytes in patients with newly diagnosed rheumatoid arthritis. Nat Commun. 2017;8:15869.

\section{Publisher's Note}

Springer Nature remains neutral with regard to jurisdictional claims in published maps and institutional affiliations.

Ready to submit your research? Choose BMC and benefit from:

- fast, convenient online submission

- thorough peer review by experienced researchers in your field

- rapid publication on acceptance

- support for research data, including large and complex data types

- gold Open Access which fosters wider collaboration and increased citations

- maximum visibility for your research: over $100 \mathrm{M}$ website views per year

At $\mathrm{BMC}$, research is always in progress.

Learn more biomedcentral.com/submissions 